\title{
Role of glutathione and other antioxidants in the inhibition of apoptosis and mesenchymal transition in rabbit lens epithelial cells
}

\author{
H.J. Wang ${ }^{1 *}$, J. Zhu ${ }^{2 *}$ and G.Y. Zheng ${ }^{1}$ \\ 'Department of Ophthalmology, \\ The First Affiliated Hospital of Zhengzhou University, \\ Zhengzhou, Henan, China \\ ${ }^{2}$ Department of Ophthalmology, \\ The First Affiliated Hospital of the Chinese PLA General Hospital, Beijing, China \\ *These authors contributed equally to this study. \\ Corresponding author: G.Y. Zheng \\ E-mail: gyzchina@yeah.net
}

Genet. Mol. Res. 13 (3): 7149-7156 (2014)

Received August 10, 2013

Accepted March 30, 2014

Published September 1, 2014

DOI http://dx.doi.org/10.4238/2014.September.1.1

\begin{abstract}
This study aimed to discuss the effect and mechanism of glutathione $(\mathrm{GSH})$ and catalase (CAT) on transforming growth factor beta (TGF- $\beta$ )-induced lens epithelial cell (LEC) apoptosis and epithelial mesenchymal transition (EMT) to prevent and control cataracts. Healthy rabbits (4 weeks old) were randomly selected, and LECs from their lenses were cultured in vitro. The 2nd- and 3rdgeneration cells were divided into 6 groups (group A: $75 \mathrm{pg} / \mathrm{mL}$ TGF- $\beta_{2}$; B: $75 \mathrm{pg} / \mathrm{mL}$ TGF- $\beta_{2}+10 \mathrm{mM}$ GSH; C: 75 pg/mL TGF- $\beta_{2}+300 \mathrm{U} /$ mL CAT; D: $10 \mathrm{mM}$ GSH; E: $300 \mathrm{U} / \mathrm{mL} \mathrm{CAT}$; and F: control group). Cell morphology was observed under an inverted microscope. The gap between cells increased, and the cells became reticulate after adding $75 \mathrm{pg} / \mathrm{mL}$ TGF- $\beta_{2}$; also, the cells swelled and appeared spindle-shaped. However, antioxidants reduced these changes. Growth inhibition was analyzed at 12,24 , and $48 \mathrm{~h}$, and the differences between groups
\end{abstract}


were not statistically significant. Cell apoptosis was analyzed, and the differences between group A and groups B and C were statistically significant $(\mathrm{P}<0.05)$. Reverse transcriptase-polymerase chain reaction was used to detect mRNA expression of $\alpha$-SMA. The $\alpha$-SMA mRNA level was greater in group $\mathrm{A}$ than in groups $\mathrm{B}$ and $\mathrm{C}(\mathrm{P}<0.05)$. TGF $-\beta_{2}$ inhibited LEC proliferation and induced apoptosis and EMT. GSH and CAT inhibited apoptosis and EMT in LECs, and they had little effect on cell proliferation. Reactive oxygen species may be involved in cell apoptosis and EMT induced by TGF- $\beta_{2}$ as a cell-signaling molecule.

Key words: Lens epithelial cells; Glutathione; Catalase; Transforming growth factor beta 2; Mesenchymal transition; Reactive oxygen species

\section{INTRODUCTION}

Cataracts are the most important etiological factor for blindness in China and the world. There are no effective methods to control them. Operation is the only effective way to cure cataracts. Some research indicated that the concentration of transforming growth factor beta 2 (TGF- $\beta_{2}$ ) in the posterior subcapsular cataract lens was higher than normal. It is therefore believed that there is an important relationship between TGF- $\beta_{2}$ and posterior subcapsular cataracts (Saika et al., 2000).

TGF- $\beta$ is the most important differentiated cell cytokine in the process of proliferation and differentiation in lens epithelial cells (LECs) (de Iongh et al., 2005). There are three isoforms: TGF- $\beta_{1}$, TGF- $\beta_{2}$, and TGF- $\beta_{3}$; TGF- $\beta_{2}$ is the most effective among the three isoforms (Saika, 2006). Hyper-concentrations of TGF- $\beta_{2}$ can induce apoptosis in LECs, while the expression of reactive oxygen species is augmented, and the active oxygen scavenging can inhibit this process (Lee et al., 2002; Tan, 2007). Reactive oxygen species, products of cell metabolism, not only cause cell apoptosis but also serve as a signal transduction molecule in many pathological processes of cells (Lee et al., 2002). We think that reactive oxygen species may be involved in TGF- $\beta_{2}$-induced LEC apoptosis as a signal transduction molecule. Glutathione (GSH) and catalase (CAT) can react with the reactive oxygen species and maintain the balance of the oxidation-reduction (redox) system.

TGF- $\beta_{2}$ can cause anterior lens capsule clouding (Saika et al., 2000), the excretion of extracellular matrix from LECs, and the induction of the epithelial-mesenchymal transition (EMT). This process would cause the capsule of the lens to become crenated and cloudy (Saika et al., 2000). $\alpha$-SMA is the identification marker of EMT occurrence (de Jong-Hesse et al., 2005), and it helps cells gain the function of infestation, ambulation, constructure, and fibrotic degeneration (Chamberlain et al., 2009). Normal LECs do not or scarcely express $\alpha$-SMA in in vitro cultures. However, LECs had positive expression of $\alpha$-SMA and fibrotic degeneration when TGF- $\beta_{2}$ was added. Therefore, it is inferred that the addition of TGF- $\beta_{2}$ may lead to some change in LECs and the excretion of $\alpha$-SMA.

In this study, rabbit LECs were used to explore the mechanism of the antioxidant effect on TGF- $\beta_{2}$-induced apoptosis and the interstitial-based mechanism of action in the process of GSH and CAT interfering with TGF- $\beta_{2}$ activity. 


\section{MATERIAL AND METHODS}

Rabbits were used for all experiments, and all procedures were approved by the Animal Ethics Committee of Zhengzhou University (Zhengzhou, China).

LECs from 30 rabbits were obtained during in vitro culture. The 4-week-old healthy rabbits were randomly selected (from the Laboratory Animal Center of Zhengzhou University) without limitations of sex and weight, and they were killed by injecting air in the ear vein. LECs were cultured in vitro from the lenses of killed rabbits. Cells were transferred when they nearly merged. The 2nd- and 3rd-generation cells were chosen for experiments and were divided into 6 groups: group A, $75 \mathrm{pg} / \mathrm{mL}$ TGF- $\beta_{2} ; \mathrm{B}, 75 \mathrm{pg} / \mathrm{mL}$ TGF- $\beta_{2}+10 \mathrm{mM} \mathrm{GSH} ; \mathrm{C}, 75 \mathrm{pg} / \mathrm{mL}$ TGF- $\beta_{2}+300 \mathrm{U} / \mathrm{mL}$ CAT; D, $10 \mathrm{mM} \mathrm{GSH}$; E, $300 \mathrm{U} / \mathrm{mL}$ CAT; and F, control (serum-free Dulbecco's modified Eagle's medium). The cell morphology was observed under an inverted microscope; the inhibition rate of LEC proliferation was assayed by 3-(4,5-dimethylthiazol-2yl)-2,5-diphenyltetrazolium bromide (MTT) at 12, 24, and $48 \mathrm{~h}$; and apoptosis was assayed by terminal deoxynucleotidyl transferase dUTP nick-end labeling (TUNEL). Reverse transcriptasepolymerase chain reaction (RT-PCR) was used to detect the $\alpha$-SMA mRNA content.

\section{Statistical analysis}

Data were analyzed with the SPSS 11.5 software. The experimental results were analyzed by single-factor variance and tested by least significant difference. $\mathrm{P}<0.05$ indicated that the difference had statistical significance.

\section{RESULTS}

\section{Cell morphology}

After 3 days, rabbit LECs lined the inner surface of the surrounding capsule, and they were nearly fused after 2 weeks. The cells were polygonal, and some of them had more than one pseudopod. Cells were translucent with abundant cytoplasm and diverse size (Figure 1A). The cells were observed under inverted microscope 24 and $48 \mathrm{~h}$ after being treated with $75 \mathrm{pg} / \mathrm{mL}$ TGF- $\beta_{2}$. These results indicated that cells became spindle-shaped, and the gap became wider like the mesh. The cells changed significantly, and some cells were lost over time (Figure 1B). When TGF- $\beta_{2}$ was added together with GSH and CAT, these changes in cell morphology were not as obvious as when TGF- $\beta_{2}$ alone was added. Individual cell appeared spindle-shaped (Figure 1C and D).
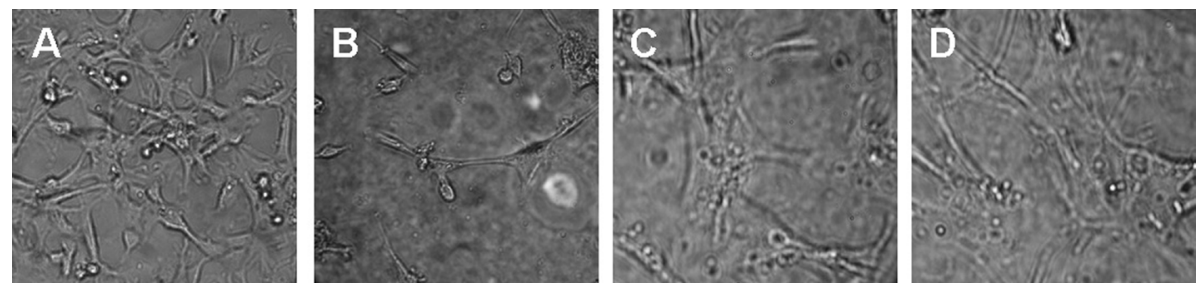

Figure 1. Cell morphology of rabbit lens epithelial cells. A. Control; B. 24 and $48 \mathrm{~h}$ after being treated with $75 \mathrm{pg} /$ mL TGF- $\beta_{2}$; C. TGF- $\beta_{2}+$ GSH; D. TGF- $\beta 2+$ CAT. 


\section{MTT assay}

The MTT assay was used to determine the rate of inhibition of cell proliferation 12, 24 , and $48 \mathrm{~h}$ after the treatment of LECs in groups A-F. The results are reported as means \pm standard deviation (Tables 1-3). The results indicated that TGF- $\beta_{2}$ inhibited LEC proliferation, and they demonstrated a definite time-effect relationship. Cell proliferation was inhibited after adding GSH and CAT, but when TGF- $\beta_{2}$ was added alone, the difference was not statistically significant.

Table 1. Effects of various processing factors on rabbit lens epithelial cell inhibition in $12 \mathrm{~h}$.

\begin{tabular}{lcc}
\hline Group & Absorbance value (OD) & Inhibition ratio (\%) \\
\hline A & $0.5412 \pm 0.0256^{*}$ & $14.6 \pm 4.62^{*}$ \\
B & $0.5358 \pm 0.0174^{* \#}$ & $15.4 \pm 5.13^{* *}$ \\
C & $0.5416 \pm 0.0339^{* \#}$ & $14.6 \pm 3.36^{* \#}$ \\
D & $0.6378 \pm 0.0357$ & $5.4 \pm 2.19$ \\
E & $0.6153 \pm 0.0264$ & $4.0 \pm 3.08$ \\
F & $0.6344 \pm 0.0254$ & - \\
P value & $<0.05$ & $<0.05$ \\
F & 15.677 & 10.710 \\
\hline
\end{tabular}

$* \mathrm{P}<0.05$ compared with the control group by single-factor variance. $\mathrm{A} P>0.05$ compared with the TGF- $\beta_{2}$ group by the LSD test.

\begin{tabular}{|c|c|c|}
\hline Group & Absorbance value (OD) & Inhibition ratio (\%) \\
\hline A & $0.4604 \pm 0.0407^{*}$ & $28.8 \pm 3.83 *$ \\
\hline B & $0.4632 \pm 0.0381$ *\# & $28.6 \pm 3.79$ *\# \\
\hline $\mathrm{C}$ & $0.4692 \pm 0.0346^{* \#}$ & $27.2 \pm 3.96$ *\# \\
\hline $\mathrm{D}$ & $0.6312 \pm 0.0219$ & $4.80 \pm 3.19$ \\
\hline E & $0.6290 \pm 0.0290$ & $2.60 \pm 1.52$ \\
\hline $\mathrm{F}$ & $0.6458 \pm 0.0390$ & - \\
\hline$P$ value & $<0.05$ & $<0.05$ \\
\hline $\mathrm{F}$ & 36.859 & 79.135 \\
\hline
\end{tabular}

${ }^{*} \mathrm{P}<0.05$ compared with the control group by single-factor variance. ${ }^{*} \mathrm{P}>0.05$ compared with the TGF- $\beta_{2}$ group by the LSD test.

Table 3. Effects of various processing factors on rabbit lens epithelial cell inhibition in $48 \mathrm{~h}$.

\begin{tabular}{lcc}
\hline Group & Absorbance value (OD) & Inhibition ratio (\%) \\
\hline A & $0.4186 \pm 0.0240^{*}$ & $34.2 \pm 2.49^{*}$ \\
B & $0.4394 \pm 0.0270^{* \#}$ & $31.0 \pm 4.18^{* \#}$ \\
C & $0.4212 \pm 0.0179^{* \#}$ & $33.6 \pm 2.50^{* \#}$ \\
D & $0.6262 \pm 0.0272$ & $3.0 \pm 1.40$ \\
E & $0.6302 \pm 0.0243$ & $1.6 \pm 1.14$ \\
F & $0.6364 \pm 0.0274$ & - \\
P value & $<0.05$ & $<0.05$ \\
F & 100.495 & 212.622 \\
\hline
\end{tabular}

$* \mathrm{P}<0.05$ compare with the control group by single-factor variance. ${ }^{*} \mathrm{P}>0.05$ compared with the TGF- $\beta_{2}$ group by the LSD test. 


\section{TUNEL assay}

A TUNEL detection kit was used to assay apoptosis $48 \mathrm{~h}$ after LECs from groups A-F. Under the fluorescence microscope, the cell nucleus of apoptotic LECs assumed green fluorescence, while the normal cell nucleus assumed no fluorescence. Nuclei from groups $\mathrm{F}$, $\mathrm{D}$, and $\mathrm{E}$ assumed green fluorescence occasionally (Figure 2A). More apoptosis (Figure 2B) occurred in LECs that were treated with $75 \mathrm{pg} / \mathrm{mL}$ TGF- $\beta_{2}$, but apoptotic cells decreased after adding GSH and CAT (Figure 2C). Each specimen was observed with a light microscope, cells and apoptotic cells were counted, and the percentage of apoptotic cells was calculated (Table 4).
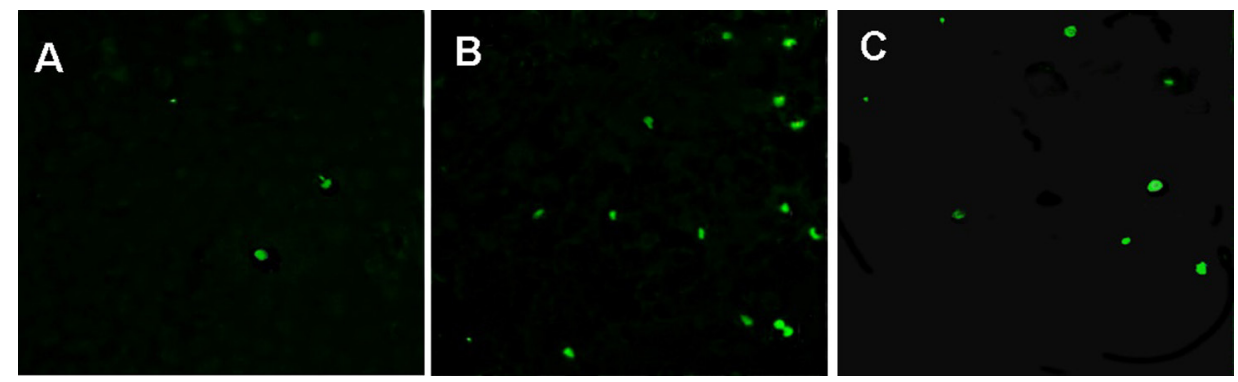

Figure 2. TUNEL detection of lens epithelial cells. A. Control; B. after being treated with $75 \mathrm{pg} / \mathrm{mL} \mathrm{TGF}-\beta_{2} ; \mathbf{C}$. after being treated with $75 \mathrm{pg} / \mathrm{mL}$ TGF- $\beta_{2}+\mathrm{GSH}+\mathrm{CAT}$.

Table 4. Effect of various processing factors on lens epithelial cell apoptosis rate (\%).

\begin{tabular}{lcc}
\hline Group & No. of cases & LEC apoptosis rate (\%) \\
\hline A & 6 & $30.78 \pm 3.17^{*}$ \\
B & 6 & $12.24 \pm 0.93^{* \#}$ \\
C & 6 & $12.76 \pm 1.13^{* \#}$ \\
D & 6 & $3.99 \pm 0.79$ \\
E & 6 & $3.91 \pm 0.88$ \\
F & 6 & $4.17 \pm 0.75$ \\
P value & & \\
F & & \\
*P $<0.05$ compared with the control group by single-factor variance. ${ }^{\#} \mathrm{P}<0.05$ compared with the TGF- $\beta_{2}$ group \\
by the LSD test.
\end{tabular}

\section{$\alpha-$ SMA}

In this study, a variety of processing factors were added to detect $\alpha$-SMA mRNA levels in LECs. RT-PCR was used to determine the $\alpha$-SMA mRNA expression relative to that of $\beta$-actin. An $\alpha$-SMA-specific product was observed in all groups and was 516 bp (Figure 3 ). The $\alpha$-SMA mRNA gray tone values were analyzed with the Quantity One software. The difference in the $\alpha$-SMA mRNA gray values between groups A-C and the control group was statistically significant $(\mathrm{P}<0.05)$. The difference between group $\mathrm{A}$ and groups $\mathrm{B}$ and $\mathrm{C}$ was also statistically significant $(\mathrm{P}<0.05)$ (Table 5). 


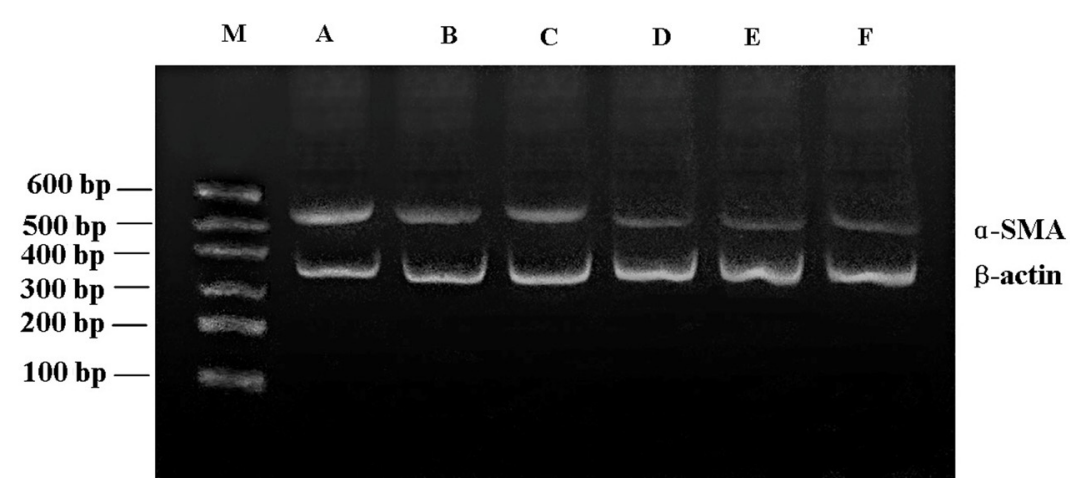

Figure 3. $\alpha$-SMA mRNA expression in each group. Lane $M=$ molecular marker.

Table 5. Effect of various processing factors on lens epithelial cell $\alpha$-SMA mRNA expression.

\begin{tabular}{|c|c|c|}
\hline Group & No. of cases & Gray value \\
\hline A & 3 & $0.863 \pm 0.020^{*}$ \\
\hline B & 3 & $0.540 \pm 0.038^{* *}$ \\
\hline $\mathrm{C}$ & 3 & $0.581 \pm 0.016^{* \#}$ \\
\hline $\mathrm{D}$ & 3 & $0.146 \pm 0.024$ \\
\hline E & 3 & $0.140 \pm 0.047$ \\
\hline $\mathrm{F}$ & 3 & $0.105 \pm 0.008$ \\
\hline$P$ value & \multirow{2}{*}{\multicolumn{2}{|c|}{$\begin{array}{c}<0.05 \\
354.875\end{array}$}} \\
\hline $\mathrm{F}$ & & \\
\hline
\end{tabular}

\section{DISCUSSION}

The oxidative stress reaction that is induced by mitochondria generates increased reactive oxygen species and leads to an imbalanced redox state. Thus, damages to the lens tissue lipid peroxide redox function are common basis of cataract diseases (Babizhayev, 2011). However, different types of cataracts behave differently. The findings of both domestic and international research on its causes and mechanisms remain controversial.

LECs maintain normal metabolism and keep the lens clear. During the embryonic development of eyes, LEC proliferation and differentiation are affected by various factors outside the cells, in which TGF- $\beta$ is one of the most important trans-differentiation cytokines (de Iongh et al., 2005). More and more studies confirm that TGF- $\beta$ can lead to the apoptosis of LECs and induce cataract formation (Sponer et al., 2005). Under physiological conditions, TGF- $\beta_{2}$ is in the inactive form, and activity can be induced by some pathological changes such as surgery and trauma (Saika et al., 2005; Ou et al., 2009). Recent studies found that high concentrations of TGF- $\beta_{2}$ can induce the apoptosis of LECs; in this process, the expression of reactive oxygen species is increased. However, apoptosis can be inhibited by adding certain antioxidants (Lee et al., 2002; Tan, 2007). During apoptosis and oxidative stress, the regulation of intracellular reactive oxygen species and GSH content may be one of the mechanisms to inhibit the apoptosis of human LECs (Ou et al., 2009). 
The main result of EMT was the loss of epithelial cell polarity and the acquisition of its mesenchymal characteristics (Thiery, 2002, 2003). $\alpha$-SMA is a marker of EMT (de Jong-Hesse et al., 2005). The increase of its secretion often marked the emergence of EMT (Ng et al., 1998). We found that TGF- $\beta_{2}$ could induce the transdifferentiation of LECs and cause the capsule to shrink or become opaque; this resulted in cortical cataracts (Saika et al., 2000). Hales et al. (1995) found that TGF- $\beta_{2}$ could induce anterior subcapsular cataracts, and the expressions of $\alpha$-SMA, type I collagen, and fibronectin around the cells were enhanced in cultured rat lens cells. Chamberlain et al. (2009) put a complete rat lens in culture medium with TGF- $\beta_{2}$. With the anterior capsule immersed in culture medium, white spots of cloudiness were observed under the capsule. The forms are similar to cortical cataracts and posterior subcapsular cataracts; LECs under the lens capsule were no longer single column-shaped, but they became spindle-shaped and they spread.

We found that TGF- $\beta_{2}$ could change the cell morphology. The change in cell morphology was reduced after adding different antioxidants to the LECs. In this study, reactive oxygen species were created during the process of TGF- $\beta_{2}$-induced morphological changes in cells, and it had certain effects on the morphological changes in cells. This conclusion agreed with the findings of Tan (2007).

Some scholars used different concentrations of TGF- $\beta_{2}$ in the human LECs. The proliferation of LECs was found to be inhibited by TGF- $\beta_{2}$, and a definite time-dose-effect relationship was detected. When the concentration of TGF- $\beta_{2}$ was over $10 \mathrm{pg} / \mathrm{mL}$, cell proliferation was inhibited $(\mathrm{P}<0.05)$, and the inhibition reached its maximum with a concentration of $100 \mathrm{pg} / \mathrm{mL}$. The effect of the inhibition did not change with increased dose and time (Tan, 2007). We also found that adding TGF- $\beta_{2}$ inhibited LEC proliferation. The inhibition did not change significantly with the addition of antioxidants. There are two possible explanations for this. The first possibility is that reactive oxygen species are not involved as cell-signaling molecules in the process of inhibiting LEC proliferation by TGF- $\beta_{2}$. The second possibility is that reactive oxygen species were involved in the TGF- $\beta_{2}$-induced inhibition process of LECs. However, there are some reasons or mechanisms that we do not understand, and this process cannot be inhibited or worsened by antioxidants. The latter can explain why the antioxidants can only delay the development of cataracts, but they cannot totally prevent and obscure cataracts in the clinical experiences (Harding et al., 1996; Ito et al., 1999; Pande et al., 2000).

Apoptosis is considered to be a cellular basis of non-congenital cataracts ( $\mathrm{Li}$ et al., 1995). Our study indicated that TGF- $\beta_{2}$ could induce the apoptosis of LECs. In addition, GSH and CAT could inhibit TGF- $\beta_{2}$-induced apoptosis. Reactive oxygen species were created during the process of TGF- $\beta_{2}$-induced apoptosis, and they played an important role in the regulation of the process.

Our study indicated that TGF- $\beta_{2}$ could increase the $\alpha$-SMA mRNA expression in LECs, LECs could enter EMT, and the process could be inhibited by the antioxidants GSH and CAT. Our observations confirmed that reactive oxygen species were involved in the TGF$\beta_{2}$-induced mesenchymal process of LECs, and they confirmed the experimental results of Yao et al. (2007).

Therefore, we believe that antioxidants may inhibit subcapsular cataracts, but they cannot totally prevent and obscure cataracts in the clinical experiences. Further research is necessary to understand the mechanisms that allowed TGF- $\beta_{2}$ to increase the reactive oxygen species expression and that allowed antioxidants to inhibit cellular apoptosis and the mesenchymal transition. 


\title{
ACKNOWLEDGMENTS
}

\author{
Research supported by the National Natural Science Foundation of China (\#81270986).
}

\section{REFERENCES}

Babizhayev MA (2011). Mitochondria induce oxidative stress, generation of reactive oxygen species and redox state unbalance of the eye lens leading to human cataract formation: disruption of redox lens organization by phospholipid hydroperoxides as a common basis for cataract disease. Cell Biochem. Funct. 29: 183-206.

Chamberlain CG, Mansfield KJ and Cerra A (2009). Glutathione and catalase suppress TGFß-induced cataract-related changes in cultured rat lenses and lens epithelial explants. Mol. Vis. 15: 895-905.

de Iongh RU, Wederell E, Lovicu FJ and McAvoy JW (2005). Transforming growth factor- $\beta$-induced epithelialmesenchymal transition in the lens: a model for cataract formation. Cells Tissues Organs 179: 43-55.

de Jong-Hesse Y, Kampmeier J, Lang GK and Lang GE (2005). Effect of extracellular matrix on proliferation and differentiation of porcine lens epithelial cells. Graefes Arch. Clin. Exp. Ophthalmol. 243: 695-700.

Hales AM, Chamberlain CG and McAvoy JW (1995). Cataract induction in lenses cultured with transforming growth factor- $\beta$. Invest. Ophthalmol. Vis. Sci. 36: 1709-1713.

Harding JJ, Blakytny R and Ganea E (1996). Glutathione in disease. Biochem. Soc. Trans. 24: 881-884.

Ito Y, Cai H, Koizumi Y, Nakao M, et al. (1999). Correlation between prevention of cataract development by disulfiram and fates of selenium in selenite-treated rats. Curr. Eye Res. 18: 292-299.

Lee JH, Wan XH, Song J, Kang JJ, et al. (2002). TGF- $\beta$-induced apoptosis and reduction of Bcl-2 in human lens epithelial cells in vitro. Curr. Eye Res. 25: 147-153.

Li WC, Kuszak JR, Dunn K, Wang RR, et al. (1995). Lens epithelial cell apoptosis appears to be a common cellular basis for non-congenital cataract development in humans and animals. J. Cell Biol. 130: 169-181.

Ng YY, Huang TP, Yang WC, Chen ZP, et al. (1998). Tubular epithelial-myofibroblast transdifferentiation in progressive tubulointerstitial fibrosis in 5/6 nephrectomized rats. Kidney Int. 54: 864-876.

Ou Y, Geng P, Liao GY, Zhou Z, et al. (2009). Intracellular GSH and ROS levels may be related to galactose-mediated human lens epithelial cell apoptosis: role of recombinant hirudin variant III. Chem. Biol. Interact. 179: 103-109.

Pande A, Pande J, Asherie N, Lomakin A, et al. (2000). Molecular basis of a progressive juvenile-onset hereditary cataract. Proc. Natl. Acad. Sci. U. S. A. 97: 1993-1998.

Saika S (2006). TGFß pathobiology in the eye. Lab. Invest. 86: 106-115.

Saika S, Miyamoto T, Kawashima Y, Okada Y, et al. (2000). Immunolocalization of TGF- $\beta 1,-\beta 2$, and - $\beta 3$, and TGF- $\beta$ receptors in human lens capsules with lens implants. Graefes Arch. Clin. Exp. Ophthalmol. 238: 283-293.

Saika S, Yamanaka O, Ikeda K, Kim-Mitsuyama S, et al. (2005). Inhibition of p38MAP kinase suppresses fibrotic reaction of retinal pigment epithelial cells. Lab. Invest. 85: 838-850.

Sponer U, Pieh S, Soleiman A and Skorpik C (2005). Upregulation of alphav $\beta 6$ integrin, a potent TGF- $\beta 1$ activator, and posterior capsule opacification. J. Cataract Refract. Surg. 31: 595-606.

Tan J (2007). Signal Transduction Mechanisms About the Effects of Transforming Growth Factor B 2 on Human Lens Epithelial Cells Apoptosis and Invasiveness. Doctoral dissertation, Zhejiang University, Hangzhou.

Thiery JP (2002). Epithelial-mesenchymal transitions in tumour progression. Nat. Rev. Cancer 2: 442-454.

Thiery JP (2003). Epithelial-mesenchymal transitions in development and pathologies. Curr. Opin. Cell Biol. 15: 740-746.

Yao K, Tan J, Gu WZ, Ye PP, et al. (2007). Reactive oxygen species mediates the apoptosis induced by transforming growth factor $\beta(2)$ in human lens epithelial cells. Biochem. Biophys. Res. Commun. 354: 278-283. 